\title{
Administração Apostólica Pessoal São João Maria Vianney: uma Reflexão Histórioa
}

\section{Personal Apostolic Administration São João Maria Vianney: a Historical Reflection}

\author{
Paulo Jonas dos Santos Júnior* \\ Pedro Henrique Caetano Figueira** \\ João Pedro Dutra Pires ***
}

Recebido em: 16/01/2020. Aceito em: 08/04/2020.

Resumo: O presente artigo busca refletir, a partir de uma leitura de base histórica, sobre um fenômeno religioso da região Norte e Noroeste do Estado do Rio de Janeiro, a Administração Apostólica Pessoal São João Maria Vianney. Após o Concílio Vaticano II, um movimento contrário aos desígnios que a Igreja Católica adotara foi responsável por um período cismático na região, de modo que os católicos mais apegados aos princípios tradicionais dessa lgreja buscavam o retorno aos costumes e doutrinas abdicados pelo novo Concílio. Ao longo deste texto foram expostos documentos históricos e religiosos que narram a trajetória do catolicismo na região Norte e Noroeste Fluminense; assim, foi possivel conhecer, de maneira mais aprofundada, as características dessa ala católica, que apesar de estar em plena comunhão com o Vaticano, mantém características próprias.

* Doutorando em Planejamento Regional e Gestão da Cidade (Universidade Cândido Mendes (UCAM), Campos dos Goytacazes, RJ). Mestre em Ciências das Religiões (Faculdade Unida de Vitória - UNIDA, Vitória, ES, 2016). Especialista em História e Cultura do Brasil (UNESA, Rio de Janeiro, 2015). Licenciado em História (ISEIB, Ibituruna, MG, 2017). Bacharel em Teologia (FAECAD, Rio de Janeiro, 2010). Psicanalista Clínico (FATEB, Rio de Janeiro, 2013).

E-mail: paulojsjunior@hotmail.com

** Graduado em História (Centro Universitário São José de Itaperuna, RJ - UNIFSJ, 2017). Graduando em Teologia (Centro Universitário São José de Itaperuna, RJ UNIFSJ).

E-mail:pedrinho_nat@hotmail.com

*** Graduando em História (Centro Universitário São José de Itaperuna, RJ - UNIFSJ). E-mail: jpdutra@hotmail.com 
Palavras-chave: Administração Apostólica. Concílio Vaticano II. Norte e Noroeste Fluminense.

Abstract: This article seeks to reflect, from a historical basis reading, on a religious phenomenon of the North and Northwest of the state of Rio de Janeiro, the Personal Apostolic Administration of St. John Mary Vianney. After the Second Vatican Council, a movement contrary to the plans adopted by the Catholic Church, was responsible for a schismatic period in the region, so that Catholics who were more attached to the traditional principles of this Church sought a return to the customs and doctrines abdicated by the new Council. . Throughout this text were exposed historical and religious documents that narrate the trajectory of Catholicism in the North and Northwest Fluminense region, and thus, it was possible to know, in a deeper way, the characteristics of this Catholic wing, which despite being in full communion with the Vatican, maintains its own characteristics.

Keywords: Apostolic Administration. Vatican Council II. North and Northwest Fluminense.

\section{Introdução}

O Concílio Vaticano II é um importante marco religioso do século XX. De caráter ecumênico, foi iniciado em 1962 e se estendeu até 1965. Esse conclave teve como produto final diversas resoluções que até hoje causam polêmica entre os cristãos, principalmente no seio da Igreja Católica Apostólica Romana, principal expoente de suas ideias.

Com o intuito de aproximar a Igreja de seus fiéis e seguidores, esse Concílio gerou preocupação na ala conservadora da Igreja Católica. Na Diocese de Campos dos Goytacazes, a recepção das decisões conciliares causou um cisma, que marcou para sempre o catolicismo na região.

Este trabalho é importante, pois aborda um acontecimento que apesar de ter ocorrido no âmbito da Igreja Católica Romana, excedeu os limites da religião e deixou profundas marcas socioculturais na região da Diocese de Campos dos Goytacazes, e mesmo após a reaproximação dos conservadores para com o papado da Igreja Católica, ainda causa pontos de tensões e distanciamentos.

Este artigo pretende, assim, discutir esse acontecimento e suas consequências, a partir de levantamento histórico. Para uma melhor compreensão do tema, foram utilizados como fonte bibliográfica, livros e periódicos especializados que debatem o assunto. 


\section{O Movimento Resistente na Diocese de Campos dos Goytacazes}

Ao esboçar a Diocese de Campos dos Goytacazes, que agrega paróquias do Norte e Noroeste Fluminense, surge de forma quase que automática a figura de Dom Antônio de Castro Mayer, que foi bispo da diocese campista em um momento crucial para história do catolicismo ${ }^{1}$.

No contexto do Concílio Vaticano II, Dom Antônio foi muito ativo e fez questão de acompanhar todas as sessões primordiais que moldaram o catolicismo e, junto com Dom Marcel Lefebvre ${ }^{2}$, se notabilizou por postura conservadora e radicalmente contra as reformas propugnadas no Concílio Vaticano $\mathrm{II}^{3}$.

Durante o Concílio, Dom Antônio militava contra as reformas na diocese na qual ele operava como Bispo Diocesano e, desta forma, diversas cartas pastorais eram publicadas e enviadas aos párocos que compunham sua cátedra diocesana. Entre muitas cartas, Dom Antônio fazia questão de estruturar suas críticas às diversas posições adotadas pelos teólogos, bispos e cardeais progressistas ${ }^{4}$. Nessas cartas, era muito comum ver considerações referentes ao modernismo, ecumenismo e à peça chave do movimento tradicional resistente, a reforma litúrgica 5 . Para Dom Antônio o modernismo deve ser analisado sob a ótica da história da Igreja, de forma a compreender suas duas facetas, o modernismo clássico, já condenado por São Pio X e o neomodernismo, que ainda estava ativo na Igreja e demonstrando suas utopias nas decisões conciliares. Dessa forma o Bispo defende que:

Modernismos são artifícios do inimigo de nossa salvação lançados como redes ou laços no meio do povo cristão, são mais perigosos do que o erro aberto, o pecado às escancaras, com que o demônio arvora cinicamente sua rebelião contra a ordem estabelecida pela Providencia. A doutrina

RIFAN, Fernando A. Sementes. Campos dos Goytacazes: CGT Editora, 2014. p. 11.

2 Dom Marcel Lefebvre foi um arcebispo católico francês que se notabilizou pela resistência às reformas da Igreja Católica instauradas pelo Concílio Vaticano II. (RIFAN, 2014, p. 10).

3 RIFAN, 2014, p. 11.

4 RIFAN, 2014, p. 13.

5 MAYER, Antônio C. Quarenta anos de episcopado. Campos dos Goytacazes: CGT Editora. 1988. p. 32. 
claramente contraria ao dogma revelado e os modos de proceder frontalmente repugnantes ao espirito de Jesus Cristo são as armas com que o demônio mantém sob seu cativeiro muitas almas e com que sustenta no mundo o ambiente propício ao pecado e à infidelidade. São coisas que devemos reprovar vivamente, e cujo desaparecimento cumpre-nos não só anelar, como por ele trabalhar empregando todos os meios ao nosso alcance.

Semelhante ambiente malsão tem, não obstante, uma consequência ainda mais nociva nos meios católicos. Ele faculta ao demônio infiltrar entre os fiéis as meias verdades e as meias virtudes, com que os faz crer que a conversão dos maus se torna mais fácil. E com isso consegue Lúcifer o que deseja, isto é, o afrouxamento da fé e o relaxamento dos costumes. Por esse declive ele leva as almas ao naturalismo e laicismo visceralmente contrários à Religião sobrenatural.

No começo deste século, São Pio X, seguindo as pegadas de seus Antecessores, denunciou, de modo ainda mais enérgico, semelhante manobra do inimigo. Fê-lo na luminosa Encíclica "Pascendi", de 8 de setembro de 1907, Encíclica que desmascara a conspiração modernista tramada por católicos entre católicos com o fim de aluir o edificio sobrenatural do Cristianismo e de qualquer religião transcendente ${ }^{6}$.

Para Dom Antônio, apesar de combatido, o modernismo ainda persistia no seio da Igreja Católica e deste modo, mesmo após a condenação deste pelo Papa Pio X através da carta encíclica Pascendi Dominis Gregis $^{7}$ o movimento continuou astuto, esperando uma oportunidade de se manifestar. A oportunidade surge, segundo Dom Antônio, através do Concílio Vaticano II, com novos modos de agir, desta vez, na figura de teólogos progressistas tendenciosos, estes que não atendiam à vontade divina que é transcendente da Igreja, mas, sim, às vontades e valores unicamente humanos ${ }^{8}$. Este novo modelo, entretanto, foi chamado de neomodernismo que, segundo Dom Antônio, apesar da repressão do Papa Pio X, continuou difuso, porém ainda bem disseminado entre os padres e teólogos conciliares:

6 MAYER, 1988, p. 45.

7 Carta encíclica de 1907 que faz críticas contundentes ao movimento modernista. (RIFAN, 2014, p. 10).

8 FIGUEIRA, Pedro H. C.; SANTOS JÚNIOR, Paulo J. Impactos do Concílio Vaticano II na Paróquia de Natividade-RJ. Unitas: Revista Eletrônica de Teologia e Ciências das Religiões, Vitória, v. 7, n. 2, p. 58-80 [p. 77], dez. 2019. Semestral. Disponível em: <http://revista.faculdadeunida.com.br/index.php/unitas/article/view/633/2136>. Acesso em: 16 dez. 2019. 
Dificilmente se encontrará entre os fiéis quem professe abertamente os princípios modernistas, o agnosticismo, o imanentismo, o evolucionismo condenado por São Pio X. Os modernistas foram sempre muito astutos, de maneira que, uma vez condenados, deixaram de se manifestar em plena luz do dia. Todavia não desarmaram. Persistem em permanecer no seio da Igreja. ${ }^{9}$

Desta forma, entende-se por neomodernismo a continuidade do movimento após as sanções dadas por Pio $\mathrm{X}$ através da carta encíclica de 1907. Dom Antônio permanecia crítico também à constituição $S a$ -

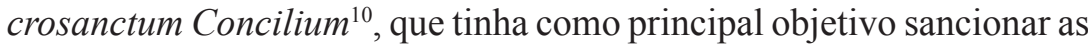
reformas litúrgicas na Igreja Católica ${ }^{11}$. Para Dom Antônio tais reformas eram respostas do modernismo militante no Vaticano II e tinham como objetivo "protestantizar" o clero romano ${ }^{12}$. Eram reestruturações profundas que tinham como objetivo deixar a liturgia mais acessível aos que pouco participavam das ações litúrgicas ${ }^{13}$. Entre as reformas litúrgicas podemos destacar a adoção da língua vernácula e as mudanças consideráveis na geografia do templo católico; adoções essas que desagradavam a Dom Antônio e todo o movimento conservador ${ }^{14}$.

Ao fim do Concílio Vaticano II, os bispos e padres conservadores tiveram pouquíssimos êxitos nas decisões norteadoras, uma vez que eram uma minoria, portanto, com pouca voz ativa ${ }^{15}$. Todavia, Dom Antônio continuou militante na causa conservadora na diocese campista, resistindo às reformas conciliares, de modo a dificultar que essas fossem efetivadas nas paróquias que agregam a Diocese de Campos dos Goytacazes $^{16}$. Dessa maneira, as paróquias e dioceses espalhadas pelo ocidente acompanhavam as reformas conciliares, e em contrapartida a Diocese de Campos duramente continuava a resistir aos avanços progressistas; Dom Antônio, inclusive, continuou a utilizar fervorosamente o rito de Pio $\mathrm{V}^{17}$.

\footnotetext{
9 MAYER, 1988, p. 43.

10 Constituição que promulgou as reformas litúrgicas. (RIFAN, 2014, p. 15).

11 ALBERIGO, Giuseppe. Breve História do Concílio Vaticano II. Aparecida: Santuário, 2006. p. 17.

12 MAYER, 1988, p. 51.

13 ALBERIGO, 2006, p. 21.

14 MAYER, 1988, p. 49.

15 ALBERIGO, 2006, p. 23.

16 RIFAN, 2014, p. 19.

17 RIFAN, 2014, p. 11.
} 
Destarte, a Diocese seguiu neste ritmo até a idade avançada de Dom Antônio de Castro Mayer, pois esse se viu obrigado a abandonar o cargo por avanço de idade. Dom Antônio, mesmo longe da cátedra de bispo diocesano, seguiu como bispo emérito, e, como militante da causa conservadora, continuou a trabalhar para a consolidação e efetiva organização do movimento tradicional na Diocese ${ }^{18}$.

Para substituir Dom Antônio de Castro Mayer, foi escolhido pelo Vaticano o bispo Dom Carlos Alberto Navarro, que apoiava as reformas conciliares. Desde sua chegada sancionou um decreto que obrigava os padres diocesanos de Campos dos Goytacazes a seguirem o novo ordo missae ${ }^{19}$, o rito já com as reformas litúrgicas ${ }^{20}$. Eis que neste contexto havia uma forte disputa ideológica, pois grande parte dos padres diocesanos não eram a favor das reformas e modificações do novo missal. Sendo assim, após o referido decreto muitos padres foram forçados a abandonar suas paróquias por desobediência, posto que esses ainda acompanhavam os preceitos do bispo emérito, Dom Antônio de Castro Mayer ${ }^{21}$. Por conseguinte, esses padres formaram a União Sacerdotal São João Maria Vianney e foram acolhidos em capelas afastadas dos grandes centros, onde continuaram a celebrar a missa de maneira irregular, ou seja, em desobediência ao decreto do bispo diocesano ${ }^{22}$. Dessa forma, os padres destoantes, incentivados por Dom Antônio, seguiram resistindo incessantemente às reformas propugnadas pelo Concílio, e um clima de guerra ideológica tomou conta da diocese campista. Padres destituídos, reintegrações de posse, perdas de cargos, isolamento pastoral e até ameaças de morte foram proferidas entre tradicionais e progressistas, momento este que teria como estopim ordenações sacerdotais sem o consentimento do Vaticano ${ }^{23}$.

18 MÉRIDA, Vinícius C. O Concílio Vaticano II, Dom Antônio de Castro Mayer e a Diocese de Campos: Resistência e Cisma. 2016a. 117 f. Dissertação (Mestrado em Ciências das Religiões) - Faculdade Unida, Vitória, ES, p. 31.

19 Novo Missal.

20 FIGUEIRA, Pedro H. C.; SANTOS JÚNIOR, Paulo J. O Concílio Vaticano II e seus desdobramentos na região norte e noroeste do Estado do Rio de Janeiro. Revista Transformar. Itaperuna, v. 1, n. 11, p.77-86 [p. 81], jun. 2017. Disponível em: <http:// www.fsj.edu.br/transformar/index.php/transformar/article/view/107/103>. Acesso em: 10 dez. 2019.

21 RIFAN, 2014, p. 29.

22 RIFAN, 2014, p. 21.

23 MÉRIDA, 2016, p. 76. 


\section{Sagração Episcopal llícita e Sem Mandato Apostólico}

Da mesma forma, Dom Marcel Lefebvre resolveu fazer a ordenação de quatro bispos sem a permissão do Vaticano, ato esse que é encarado como cismático, pois se configura como uma desobediência ao Papa e à autoridade da Igreja. Esse fato ocorreu no dia 28 de julho de 1991, na cidade de São Fidélis - na região Norte Fluminense - no ensejo em que o Padre Licínio Rangel foi sagrado Epíscopo, "sem jurisdição, apenas com poder de Ordem para atender aos fiéis da linha tradicional" ${ }^{24}$, em cerimônia solene na Paróquia Pessoal Nossa Senhora Aparecida e São Fidélis, ainda em processo de construção na época. O fato trouxe novos ares ao tradicionalismo católico fluminense, quiçá do mundo inteiro. Porém, a partir de então, inevitavelmente, se deu a excomunhão de todos que aderiram ou concordam com as ordenações, e juntamente a esse atose concretizou o cisma católico, ancorado na figura dos resistentes e seguidores de Dom Antônio de Castro Mayer ${ }^{25}$.

A cerimônia de ordenação foi presidida por Dom Bernard de Tissier, tendo como co-sagrantes os epíscopos Dom Alfonso de Galarreta e Dom Richard Williamsom ${ }^{26}$ e presença de clérigos da Fraternidade Sacerdotal São Pio $X^{27}$, bem como dos sacerdotes integrantes da União Sacerdotal campista. Tal evento foi amplamente difundido nos meios de notícia pelo país ${ }^{28}$. A sagração de Dom Licínio Rangel fora solicitada pela União Sacerdotal à Fraternidade Sacerdotal, pois julgavam "algo necessário, devido à crise, um caso de necessidade" 29 , mediante a situação religiosa vivenciada na época. Contudo, os epíscopos sagrantes de Dom Licínio não solicitaram mandato apostólico à Santa Sé, e a fim de respaldarem a

\footnotetext{
24 RIFAN, 2014, p. 30.

25 RIFAN, 2014, p. 26.

26 MARÇAL. Emílio. Dossiê FSSPX: Parte III. São Paulo: Direito da Sacristia, 2018. Não paginado. Disponível em: <http://diretodasacristia.com/home/curia-romana/dossie-fsspx-parte-iii/>. Acesso em: 13 set. 2019.

27 A Fraternidade Sacerdotal São Pio X (FSSPX) é uma sociedade que defende o tradicionalismo católico romano. Foi fundada em 1970 pelo Bispo Marcel Lefebvre, com o intuito de preservar a Missa Tridentina e o padrão de fé e religiosidade anteriores ao Concílio Vaticano II. (RIFAN, 2014, p. 12).

28 O fato teve manchete na edição de 29 de julho de 1991 do Jornal O Globo. Cf. CAMPOS. Sagração D. Licínio Rangel por D. Tissier de M. em S. Fidelis. São Fidélis: [s.i.], 1991. (4 min.), son., color. Disponível em: <https://www.youtube.com/watch?time_co ntinue $=1 \& v=x$ DkcQc0PrzU\&feature=emb_title $>$. Acesso em: 14 jan. 2020.
} 
ação, usaram-se do entendimento de "estado de necessidade" ${ }^{30}$, tal como os grupos originados da Fraternidade Sacerdotal São Pio X ainda fazem uso. As autoridades eclesiásticas, neste contexto estavam completamente alheias às intenções e fatos que se descortinavam no interior do Norte e Noroeste Fluminense ${ }^{31}$. $\mathrm{O}$ ato de sagrar Bispo sem mandato apostólico, apesar de constituir fator inegável de sucessão apostólica, ou seja, de validade sacramental, constitui pela perspectiva da Santa Sé, cisma e excomunhão automática dos epíscopos que acompanharam a cerimônia como sagrantes ${ }^{32}$.

Os sagrantes de Dom Licínio foram penalizados por meio de Decreto do Prefeito desta Congregação, no dia 1 de julho de 1988, ou seja, um dia após a cerimônia campal que contou com larga participação dos fiéis e clérigos tradicionalistas, inclusive de Padre Rifan ${ }^{33}$, secretário pessoal de D. Mayer. Cabe expor que essas penalizações só foram levantadas pela Congregação para os Bispos em 21 de janeiro de 2009, sob o papado de Bento XVI, a fim de:

consolidar as recíprocas relações de confiança e intensificar e dar estabilidade à ligação da Fraternidade São Pio X com esta Sé Apostólica. Este dom de paz, no termo das celebrações natalícias, pretende também ser um sinal para se promover a unidade na caridade da Igreja universal e chegar à eliminação do escândalo da divisão. ${ }^{34}$

O temor das excomunhões não atingiu de forma incisiva o coração dos fiéis tradicionalistas atendidos pelos sacerdotes da União Sacerdotal. Ao contrário, foram confortados por inúmeros meios físicos - livretos, folhetos, além da pregação - lançados pela mesma União, que deu respaldo, dentro de sua perspectiva, ao gravíssimo caso de necessidade diante da "Roma de tendência neo-modernista e neo-protestante que

30 MANDATO Apostólico. Não paginado. Disponível em: <http://beneditinos.org. br/2016/03/mandato-apostolico/>. Acesso em: 13 set. 2019.

31 MÉRIDA, Vinícius C. A tardia e conflituosa recepção do Concílio Vaticano II na diocese de Campos dos Goytacazes. Revista Transformar. 2016b, v. 8, n. 8, p. 147.

32 MÉRIDA, 2016b, p. 146.

33 SAGRAÇÃO Episcopal em 1988 - Econe 30 de junho. Écône: [s.i.], 1988. (24 min.), son., color. Legendado. Disponível em: <https://www.youtube.com/ watch?v=FLyOLq8GDug>. Acesso em: 14 jan. 2020.

34 BENTO XVI. Decreto 21 de janeiro de 2009. Vaticano: 2009. Não paginado. Disponível em: <http://www.vatican.va/roman_curia/congregations/cbishops/documents/ rc_con_cbishops_doc_20090121_remissione-scomunica_po.html>. Acesso em: 14 set. $20 \overline{19}$. 
se manifestou claramente no Concílio Vaticano II" e se impôs sobre os "legítimos católicos apostólicos romanos". ${ }^{35}$

\section{A Reaproximação com a Santa Sé}

O período que se sucedeu após as sagrações de Ècone e São Fidélis, em 1988 e 1991, respectivamente, foram acompanhadas de situações fatídicas no seio da Fraternidade Sacerdotal São Pio X, bem como da União Sacerdotal São João Maria Vianney. Em 1991, falecem os epíscopos Dom Mayer ${ }^{36}$ e Dom Lefebvre ${ }^{37}$, o que gerou um abalo momentâneo nos grupos tradicionais.

Foi nesse contexto que se deu a sagração ilícita e sem mandato de Dom Licínio Rangel, realizada para atender as necessidades sacramentais dos fiéis tradicionalistas brasileiros ligados à União Sacerdotal São João Maria Vianney, em 1992. Além disso, a Fraternidade Sacerdotal São Pio X se expandiu para as Filipinas e, em 1994, se deu a eleição de D. Bernard Fellay que, a partir de então, ficou conhecido como um enérgico defensor da Tradição entre os Bispos da Fraternidade.

Dessa maneira, a Tradição Católica presenciou um momento de bonança, anômalo aos momentos mais furtivos de lutas eclesiásticas que vivenciara nos anos precedentes ao falecimento dos baluartes da resistência. Sobre esse momento, Padre Hélio Marcos da Silva Rosa, então sacerdote da União Sacerdotal, comenta:

[Dom Marcel Lefebvre] Tinha 65 anos de idade quando começou esta obra nova, e 83 anos quando, com Dom Antônio, sagrou quatro bispos para a sobrevivência da Tradição, vida da santa Igreja. [...] apesar dos obstáculos: o número dos sacerdotes se duplicou (agora 400), e mais de

35 RIFAN, Fernando A. Folheto Esclarecimento sobre a Sagração de Bispos. Não paginado. Disponível em: <https://www.fsspx.com.br/esclarecimento-sobre-a-sagracao-de-bispos-pe-fernando-rifan/>. Acesso em: 14 set. 2019.

36 Dom Antônio de Castro Mayer faleceu em 26 de abril de 1991, foi sepultado na Capela da Ordem Terceira do Carmo, em Campos dos Goytacazes. (ROSA, Hélio M. S. Dom Marcel Lefebvre e Dom Antônio de Castro Mayer: 10 anos de falecimento. Revista Ontem Hoje Sempre. n. 63. Campos dos Goytacazes, 2001. Não paginado. Disponível em: <https://www.fsspx.com.br/dom-marcel-lefebvre-e-dom-antonio-de-castro-mayer-10-anos-de-falecimento/>. Acesso em: 14 set. 2019).

37 Dom Marcel Lefebvre faleceu em 25 de março de 1991, foi sepultado no Seminário da FSSPX em Ėcone. (ROSA, 2001, não paginado). 
cinquenta igrejas ou capelas foram construidas no mundo, sem falar da multiplicação dos priorados, escolas, colégios, e outras obras. ${ }^{38}$

Apesar dos ares favoráveis à Tradição Católica, os anos seguintes à sagração de Dom Licínio Rangel trouxeram rupturas e fragilidades de pensamentos, ideais e ainda rompimento entre a Fraternidade Sacerdotal e a União Sacerdotal, uma vez que despertou-se entre os sacerdotes tradicionalistas de Campos dos Goytacazes o sentimento de culpabilidade perante a falta de comunhão com Roma, e que "incomodava cada vez mais a consciência" 39 de todos. Assim, em pleno Ano Jubilar convocado pelo Papa João Paulo II, os grupos tradicionais - União Sacerdotal e Fraternidade Sacerdotal - organizaram uma peregrinação a Roma, encabeçada por seu Superior Geral, eleito em 1994, que "conduziu em peregrinação a Roma todos os seus sacerdotes, religiosos e seminaristas, esperando, assim, poder expressar o seu amor e respeito pelo Santo Padre." ${ }^{\prime 4}$. Essa peregrinação a Roma levou mais de 5.000 fiéis tradicionais a entrarem na Basílica de São Pedro em solene prece peregrina.

Essa iniciativa gerou no Vaticano uma percepção de que seria possível uma reaproximação entre os fiéis tradicionalistas e a Igreja Católica Romana. Assim, o Papa João Paulo II convida o Cardeal Darío Castrillón Hoyos, Prefeito da Congregação para o Clero e da Pontifícia Comissão Ecclesia Dei, a dar início às conversações com os tradicionalistas. Por meio dele, a Santa Sé propôs então uma reconciliação aos padres tradicionalistas ${ }^{41}$.

O Cardeal, "impressionado favoravelmente por essa demonstração de catolicidade" "42, ofereceu a boa vontade da Santa Sé em buscar uma solução que apaziguasse as relações, o que poderia culminar na comunhão plena com a Igreja. Entretanto, a recepção da proposta do Vaticano foi diferente entre a União Sacerdotal e a Fraternidade Sacerdotal.

38 ROSA, 2001, não paginado.

39 RIFAN, 2014, p. 30.

40 FRATERNIDADE SACERDOTAL DE SÃO PIO X. Um grandioso mistério. Não paginado. Disponível em: <https://www.fsspx.es/pt/um-grandioso-mist\%C3\%A9rio>. Acesso em: 14 set. 2019.

41 RIFAN, 2014, p. 35.

42 FRATERNIDADE SACERDOTAL DE SÃO PIO X. Peregrinação a Roma e o combate doutrinal. Não paginado. Disponível em: <https://fsspx.org/pt/peregrinacao-roma-e-o-combate-doutrinal>. Acesso em: 12 jan. 2020. 
Nessa perspectiva, porém, decorreram algumas divergências no entendimento da conversação entre o Cardeal Hoyos e o líder da Fraternidade Sacerdotal, Dom Fellay. Dessa forma, o Superior Geral da Fraternidade Sacerdotal de São Pio X demanda ao Cardeal:

dois sinais de paz, capazes de mostrar que algo finalmente mudou no Vaticano. Pede a liberalização da Missa tradicional para todos os sacerdotes católicos e o levantamento das censuras injustas que pesam sobre os bispos supostamente excomungados desde 1988 e que são uma espécie de marca de infâmia lançada contra a Igreja de sempre. ${ }^{43}$

Assim, apesar de Dom Fellay, representante da Fraternidade Sacerdotal de São Pio X e Dom Hoyos, representante do Vaticano, não terem conseguido uma reaproximação definitiva entre as entidades, a União Sacerdotal São João Maria Vianney recebeu as propostas do Vaticano e ponderou para que a comunhão com Roma fosse finalmente celebrada. Dessa forma, a boa vontade da Santa Sé "foi largamente discutida por Dom Licínio com todos os padres [...] durante cerca de um ano" ${ }^{44}$, o que resultou em um retiro espiritual entre os sacerdotes, de quase uma semana, oportunidade essa em que debateram profundamente sobre a proposta. Em 15 de agosto de 2001, Padre Fernando Rifan dirigiu-se a Roma como portador de uma carta em nome de todos os padres integrantes da União Sacerdotal, a qual foi entregue ao Papa por intermédio de Dom Hoyos. A resposta positiva para a reaproximação de João Paulo II deu-se meses depois, pela Carta Autógrafa Ecclesiae Unitas. À vista disso, o Papa João Paulo II, mediante as conversações com o clero da União Sacerdotal, retirou "a excomunhão de Dom Licínio Rangel em novembro de $2001 " 45$, bem como as punições determinadas pelo Direito Canônico ${ }^{46}$; igualmente, deu-se, então, o reconhecimento papal da União

\footnotetext{
43 FSSPX, 2020, não paginado.

44 RIFAN, 2014, p. 35.

45 RIFAN, Fernando A. Carta enviada para os Bispos da FSSPX: Destinatários - Dom Bernard Fellay, Dom Bernard Tissier de Mallerais, Dom Richard Williamsom e Dom Alfonso Galarreta. 2009. Não paginado. Disponível em: <https://docplayer.com. br/42465417-Dom-fernando-areas-rifan.html>. Acesso em: 14 set. 2019.

O Código de Direito Canônico, no $n^{\circ} 1382$, determina que o "Bispo que, sem o mandato pontifício, confere a alguém a consagração episcopal e, igualmente, quem dele recebe a consagração incorrem em excomunhão latae sententiae reservada à Sé Apostólica". (JOÃO PAULO II, Papa. Código de Direito Canônico. Título III - Da usurpação das funções eclesiásticas e dos delitos no exercício das mesmas, p. 240. Disponível em: <http://www.vatican.va/archive/cod-iuris-canonici/portuguese/codex-iuris-canonici_po.pdf>. Acesso em: 14 set. 2019).
} 
Sacerdotal São João Maria Vianney, que fora transformada pelo próprio pontífice em Administração Apostólica Pessoal São João Maria Vianney.

\section{Ereção da Administração Apostólica Pessoal}

Em 18 de Janeiro de 2002, por meio do Documento Animarum Bonum da Congregação para os Bispos - em conformidade com a vontade do então Papa João Paulo II47, expressa pela Carta Ecclesiae Unitas, deu-se o reconhecimento de direito da Administração Apostólica Pessoal São João Maria Vianney, bem como a concessão de permissão de sede episcopal, à Igreja Principal do Imaculado Coração de Nossa Senhora de Fátima $^{48}$. Vale ressaltar que a Administração Apostólica Pessoal é uma circunscrição eclesiástica que equipara-se à Diocese, sendo aquela em específico, de cunho pessoal, tendo jurisdição sobre os fiéis da Forma Extraordinária do Rito Romano, com livre possibilidade de incardinação destes, entretanto, sem delimitação territorial. A esse respeito, faz-se necessário reproduzir as palavras de Dom Fernando Arêas Rifan:

O Papa transforma assim a união sacerdotal em Administração Apostólica, para regularizar aquela situação anômala e conservar na plena comunhão da Igreja esses sacerdotes (eram 25) e fiéis ligados às formas litúrgicas e disciplinares anteriores do Rito Romano. [...] A história de momentos tristes terminou com um final feliz, com a criação da Administração Apostólica Pessoal São João Maria Vianney, que devolveu aos 'padres de Campos' a faculdade de ter paróquias e o privilégio de conservarem a Missa na forma antiga.

A posição adotada pelos "Padres tradicionalistas de Campos" mediante a criação da Administração Apostólica Pessoal em reconhecer plenamente as faculdades hierárquicas das autoridades eclesiásticas, bem como o pleno devotamento ao esforço de prosseguir em comunhão com a Igreja, representa um significativo avanço no movimento de resistência católica em Campos dos Goytacazes ${ }^{49}$. Apesar da manifesta intenção em manter o "espírito" do Concílio Vaticano II e da acepção da

$47 \quad$ RIFAN, 2014, p. 38.

48

CONFERÊNCIA NACIONAL DOS BISPOS DO BRASIL. Decreto Animarum Bonum. Brasília, 2002. p. 6, Doc. 13. Disponível em: <https://cnbbleste1.org.br/dioceses/adm-apostolica-sao-joao-maria-vlanney/>. Acesso em: 10 jan. 2020.

49 UNIÃO SACERDOTAL SÃO JOÃO MARIA VIANNEY. Missa Nova: Um caso de consciência. Campos dos Goytacazes: Santuário, 2009. p. 2. 
Forma Ordinária do Rito Romano como santificante e veículo de graça não diferente da Forma Extraordinária - reproduzida nas Paróquias Pessoais - a Santa Sé evidencia posições de forte vigilância, ou ainda, preocupação pastoral ${ }^{50}$.

A ereção da Administração Apostólica pela Santa Sé e o reconhecimento de direitos por parte da Congregação para os Bispos (aqui pode-se inferir inclusive o apreço de Prelados brasileiros por meio da ereção canônica) tal como assegurados no - já referenciado-Animarum Bonum, inserem-se em meio à atenção dos órgãos romanos para a manutenção do novo pensamento do clero tradicional campista51. Além da submissão ao Bispo Diocesano de Campos, quer por meio da necessidade deste para resolução de problemas judiciais quer pela autoridade em sua circunscrição eclesiástica, a Santa Sé obriga ao Administrador Apostólico visita ad limina apostolorum a fim de submeter ao Pontífice relatórios frequentes da situação em sua Administração Apostólica Pessoal ${ }^{52}$.

Os privilégios despendidos aos tradicionalistas de Campos não se limitavam apenas à plena comunhão da Administração Apostólica São João Maria Vianney ${ }^{53}$ com o Vaticano, uma vez que, tal como vistas no Documento de Ereção, as concessões são generosas, e incluem: direito de celebração da Eucaristia e dos demais Sacramentos, dos Ofícios do Breviário Romano (Liturgia das Horas), mediante o Missal de 1962 promulgado pelo Papa João XXIII ${ }^{54}$; a permissão de incardinação de leigos e sacerdotes de outras circunscrições eclesiásticas ${ }^{55}$ - que inclusive mantém sacerdotes de outros países ${ }^{56}$-; liberdade de criação de Institutos e Apostolados ${ }^{57}$, e além desses, a ereção do Seminário da Imaculada

50 UNIÃO SACERDOTAL SÃO JOÃO MARIA VIANNEY. Informe Doutrinário Católicos Apostólicos Romanos: Nossa posição, na atual situação da Igreja. Campos dos Goytacazes: Santuário, 1999. p. 53.

JOÃO PAULO II. Motu Proprio Ecclesia Dei Adflicta, Vaticano, 1988, não paginado. Disponível em: <http://w2.vatican.va/content/john-paul-ii/pt/motu_proprio/documents/ hf_jp-ii_motu-proprio_02071988_ecclesia-dei.html>. Acesso em: 20 jan. 2020.

CNBB, 2002, p. 10.

ADMINISTRAÇÃO APOSTÓLICA PESSOAL SÃO JOÃO MARIA VIANNEY. Clero da Administração Apostólica. 2008, não paginado. Disponível em: <https://www.adapostolica.org/clero/>. Acesso em: 13 set. 2019. CNBB, 2002, p. 13. 
Conceição $0^{58}$ para formação sacerdotal mediante as "características próprias" 59 do pensamento tradicionalista de Campos dos Goytacazes. Torna-se aqui mister expor que esses vastos privilégios não são exclusivos à Administração Apostólica Pessoal de Campos, todavia, são concebidos a pouquíssimos grupos com particularidades no seio da Igreja.

\section{Sagração Episcopal do Padre Fernando Rifan}

O Padre Fernando Rifan foi sagrado Bispo em 18 de Agosto de 2002, na Forma Extraordinária do Rito Romano pelas mãos de Dom Hoyos; ele havia promovido as conversações entre a então União Sacerdotal e a Santa Sé, por ocasião do Ano Jubilar de 2000. Os co-sagrantes foram Dom Alano Maria Penna e Dom Licínio Rangel, este último, já debilitado por ter sido acometido por um câncer. A cerimônia ocorreu na cidade de Campos dos Goytacazes, contando com a presença de importantes autoridades eclesiásticas, tais como Dom Carlos Alberto Navarro (que fora Bispo diocesano de Campos), Dom Manoel Pestana Filho, "centenas de sacerdotes vindos da Administração Apostólica Pessoal, da Diocese de Campos e de várias partes do Brasil e do exterior, com o concurso de sete mil fiéis." $" 60$

O direito de sucessão de Dom Licínio fora assegurado pelo Papa João Paulo II por meio de sua carta Ecclesiae Unitas, ao passo que definira o antigo Prelado da União Sacerdotal como o primeiro Administrador Apostólico da recém-fundada Administração Apostólica. Tendo seu Administrador debilitado pela doença física, o Papa João Paulo II nomeou o então Padre Fernando Rifan como Bispo Coadjutor em 28 de Junho de 2002, em resposta aos anseios de continuidade da Tradição ${ }^{61}$. Dom Licínio Rangel faleceu meses após a cerimônia dessa Sagração Episcopal, mais precisamente, em 16 de Dezembro. Segundo sua biografia, por meio de seu último suspiro, recitou versos da Prece Mariana Sub Tuum Praesidium, que era lema gravado em seu Brasão Episcopal ${ }^{62}$.

$58 \quad$ CNBB, 2002, p. 8.

59 SEMINÁRIO DA IMACULADA CONCEIÇÃO. Sobre nós. Disponível em: <http://www. seminarioic.org/oseminario/>. Acesso em: 13 de set. 2019.

60 RIFAN, 2014, p. 45.

61 RIFAN, 2014, p. 43.

62 DEUS tem seus caminhos: Homenagem a Dom Licínio Rangel e Alguns dados da vida de Dom Licínio Rangel, primeiro Administrador Apostólico, falecido ao 16/12/2002. 2011. Disponível em: <https://geracaodesantos.blogspot.com/2011/12/deus-tem-seus-caminhos-homengem-dom.html>. Acesso em: 12 jan. 2020. 
Tendo decorrido seu falecimento, Dom Fernando Arêas Rifan tornou-se automaticamente o Administrador Apostólico dos tradicionalistas de Campos dos Goytacazes.

\section{Ao Agrado da Santa Sé, ao Desagrado da Resistência Católica}

Os reflexos do acordo dos tradicionalistas de Campos com a Santa Sé e a consequente Sagração Episcopal do Padre Fernando Rifan foram prontamente respondidos no meio tradicional católico mundial, com grande impacto entre os resistentes à comunhão e aos acordos com Roma no Brasil. A Fraternidade Sacerdotal São Pio X, até então aliada aos padres tradicionalistas de Campos, tomou posturas enérgicas e criticou duramente o novo rumo que o movimento tradicional do Norte Fluminense tinha tomado.

Em Aparecida do Norte, no Santuário Nacional, foi celebrada uma Missa no dia 8 de setembro de 2004, que comemorou o centenário de coroação da Imagem de Nossa Senhora Aparecida, e contou com a concelebração de inúmeros epíscopos e sacerdotes do Brasil, "entre os quais Dom Fernando Rifan e o padre Claudiomar Silva Souza da Administração Apostólica Pessoal São João Maria Vianney de Campos dos Goytacazes" $"$. A presença dos sacerdotes tradicionalistas da Administração Apostólica de Campos dos Goytacazes nessa celebração, presidida pelo Cardeal Dom Eugênio Sales, gerou um grande mal-estar no âmbito dos resistentes da Fraternidade Sacerdotal São Pio X, bem como de outros grupos tradicionalistas do país e do mundo, os quais, além de aproveitarem o fato ocorrido pouco após o acordo com a Santa Sé para denunciarem publicamente os ditos erros da Nova Missa ${ }^{64}$, interpretaram a participação de Dom Rifan e do então Responsável de Liturgia da Administração Apostólica, Padre Claudiomar, na celebração em Aparecida do Norte, como profunda demonstração de "mudança doutrinal da Administração de Dom Rifan"65.

63 FRATERNIDADE SACERDOTAL DE SÃO PIO X. Boletim Guarde a Fé. n. 22. Santa Maria, Janeiro e Fevereiro de 2005, p. 1.

64 Tal como lê-se no Boletim Guarde a Fé, da Fraternidade Sacerdotal São Pio X: "[...] esse contexto não impediu o desprezo explícito das normas definidas 'por mandato do Sumo Pontífice' [...] esses fatos são como uma gota no que podemos chamar o 'tsunami' modernista que arrasta as almas [...]" (FSSPX, 2005, p. 2).

65 FRATERNIDADE SACERDOTAL DE SÃO PIO X. Fotos Reveladoras. 2010, não paginado. Disponível em: <https://www.fsspx.com.br/fotos-reveladoras/>. Acesso em: 14 set. 2019. 
Segundo a Administração Apostólica Pessoal São João Maria Vianney, ao final do ano de 2019, a instituição contava com 12 Paróquias e 2 Quase-Paróquias, as quais cobriam diversas cidades do Norte e do Noroeste do Rio de Janeiro, além de igrejas, capelas e comunidades em outros municípios do mesmo Estado e em outras frações da federação. Para atender seus fiéis, no mesmo ano, a instituição dizia possuir 35 padres e um bispo $^{66}$.

\section{Considerações Finais}

O presente artigo buscou apresentar a trajetória histórica da Administração Apostólica Pessoal São João Maria Vianney, instalada em Campos dos Goytacazes, na região Norte do Estado do Rio de Janeiro. Ao longo do trabalho foi possível observar como o tradicionalismo, defendido por um expressivo número de católicos do Norte e do Noroeste Fluminense, foi responsável por um fenômeno praticamente único na região, a existência de dois bispos com autoridade eclesiástica ligadas ao papado e ao Vaticano.

Assim, a história da Administração Apostólica Pessoal São João Maria Vianney pode nos mostrar que, apesar de momentos de divergências doutrinárias e ideológicas, a unidade da fé pode ser mantida, com o objetivo de conservar a Igreja Católica, a fé cristã e a Tradição Apostólica.

\section{Referências Bibliográficas}

ADMINISTRAÇÃO APOSTÓLICA PESSOAL SÃO JOÃO MARIA VIANNEY. Clero da Administração Apostólica. 2008, não paginado. Disponível em: <https://www.adapostolica.org/clero/>. Acesso em: 13 set. 2019.

ADMINISTRAÇÃO APOSTÓLICA PESSOAL SÃO JOÃO MARIA VIANNEY. Lista dos Sacerdotes e Cargos. 2020. Disponível em: $<$ https:// www.adapostolica.org/lista-dos-sacerdotes-e-cargos-2020/>. Acesso em: 12 jan. 2020.

66 ADMINISTRAÇÃO APOSTÓLICA PESSOAL SÃO JOÃO MARIA VIANNEY. Lista dos Sacerdotes e Cargos. 2020. Disponível em: <https://www.adapostolica.org/lista-dos-sacerdotes-e-cargos-2020/>. Acesso em: 12 jan. 2020. 
ALBERIGO, Giuseppe. Breve História do Concílio Vaticano II. Aparecida: Santuário, 2006. p. 17.

BENTO XVI. Decreto 21 de janeiro de 2009. Vaticano: 2009. Não paginado. Disponível em: $<$ http://www.vatican.va/roman_curia/congregations/cbishops/documents/rc_con_cbishops_doc_20090121_remissione-scomunica_po.html>. Acesso em: 14 set. 2019.

CONFERÊNCIA NACIONAL DOS BISPOS DO BRASIL. Decreto Animarum Bonum. Brasília, 2002, p. 6; Doc. 13. Disponível em: $<$ https:// cnbbleste1.org.br/dioceses/adm-apostolica-sao-joao-maria-vlanney/>. Acesso em: 10 jan. 2020.

DEUS tem seus caminhos: Homenagem a Dom Licínio Rangel e Alguns dados da vida de Dom Licínio Rangel, primeiro Administrador Apostólico, falecido ao 16/12/2002. 2011. Disponível em: <https://geracaodesantos.blogspot.com/2011/12/deus-tem-seus-caminhos-homengem-dom. html>. Acesso em: 12 jan. 2020.

FIGUEIRA, Pedro H. C.; SANTOS JÚNIOR, Paulo J. Impactos do concílio vaticano II na paróquia de natividade-RJ. Unitas: Revista Eletrônica de Teologia e Ciências das Religiões. Vitória, v. 7, n. 2, p. 58-80 [p. 77], dez. 2019. Semestral. Disponível em: $<$ http://revista.faculdadeunida.com. br/index.php/unitas/article/view/633/2136>. Acesso em: 16 dez. 2019.

FIGUEIRA, Pedro H. C.; SANTOS JÚNIOR, Paulo J. O Concílio Vaticano II e seus desdobramentos na região norte e noroeste do Estado do Rio de Janeiro. Revista Transformar. Itaperuna, v. 1, n. 11, p. 77-86 [p. 81], jun. 2017. Disponível em: <http://www.fsj.edu.br/transformar/ index.php/transformar/article/view/107/103>. Acesso em: 10 dez. 2019.

FRATERNIDADE SACERDOTAL DE SÃO PIO X. Boletim Guarde a $F e ́$. n. 22. Santa Maria, Janeiro e Fevereiro de 2005, p. 1.

FRATERNIDADE SACERDOTAL DE SÃO PIO X. Fotos Reveladoras. 2010, não paginado. Disponível em: $<$ https://www.fsspx.com.br/fotos-reveladoras/>. Acesso em: 14 set. 2019.

FRATERNIDADE SACERDOTAL DE SÃO PIO X. Peregrinação $a$ Roma e o combate doutrinal. Não paginado. Disponível em: $<\mathrm{https}: / /$ fsspx.org/pt/peregrinacao-roma-e-o-combate-doutrinal $>$. Acesso em: 12 jan. 2020. 
FRATERNIDADE SACERDOTAL DE SÃO PIO X. Um grandioso mistério. Não paginado. Disponível em: < https://www.fsspx.es/pt/um-grandioso-mist\%C3\%A9rio>. Acesso em: 14 set. 2019.

JOÃO PAULO II, Papa. Código de Direito Canônico. Título III - Da usurpação das funções eclesiásticas e dos delitos no exercício das mesmas, p. 240. Disponível em: $<$ http://www.vatican.va/archive/cod-iuris-canonici/ portuguese/codex-iuris-canonici_po.pdf $>$. Acesso em: 14 set. 2019.

JOÃO PAULO II. Motu Proprio Ecclesia Dei Adflicta, Vaticano, 1988, não paginado. Disponível em: $<$ http://w2.vatican.va/content/john-paul-ii/ pt/motu_proprio/documents/hf_jp-ii_motu-proprio_02071988_ecclesia-dei.html>. Acesso em: 20 jan. 2020.

MANDATO Apostólico. Não paginado. Disponível em: $<$ http://beneditinos.org.br/2016/03/mandato-apostolico/>. Acesso em 13 set. 2019.

MARÇAL. Emílio. Dossiê FSSPX: Parte III. São Paulo: Direito da Sacristia, 2018. Não paginado. Disponível em $<$ http://diretodasacristia.com/ home/curia-romana/dossie-fsspx-parte-iii/>. Acesso em: 13 set. 2019.

MAYER, Antônio C. Quarenta anos de episcopado. Campos dos Goytacazes: CGT Editora, 1988. p. 32.

MÉRIDA, Vinícius C. A tardia e conflituosa recepção do Concílio Vaticano II na diocese de Campos dos Goytacazes. Revista Transformar. 2016b, v. 8, n. 8, p. 147.

MÉRIDA, Vinícius C. O Concílio Vaticano II, Dom Antônio de Castro Mayer e a Diocese de Campos: Resistência e Cisma. 2016a. 117 f. Dissertação (Mestrado em Ciências das Religiões) - Faculdade Unida, Vitória-ES, p. 31.

RIFAN, Fernando A. Carta enviada para os Bispos da FSSPX: Destinatários - Dom Bernard Fellay, Dom Bernard Tissier de Mallerais, Dom Richard Williamsom e Dom Alfonso Galarreta. 2009. Não paginado. Disponível em: <https://docplayer.com.br/42465417-Dom-fernando-areas-rifan.html>. Acesso em: 14 set. 2019.

RIFAN, Fernando A. Sementes. Campos dos Goytacazes: CGT Editora, 2014. p. 11.

RIFAN, Fernando A. Folheto Esclarecimento sobre a Sagração de Bispos. Não paginado. Disponível em: <https://www.fsspx.com.br/ 
esclarecimento-sobre-a-sagracao-de-bispos-pe-fernando-rifan/>. Acesso em: 14 set. 2019.

ROSA, Hélio M. S. Dom Marcel Lefebvre e Dom Antônio de Castro Mayer: 10 anos de falecimento. Revista Ontem Hoje Sempre. n. 63. Campos dos Goytacazes, 2001. Não paginado. Disponível em: $<$ https://www. fsspx.com.br/dom-marcel-lefebvre-e-dom-antonio-de-castro-mayer-10-anos-de-falecimento/>. Acesso em: 14 set. 2019

SAGRAÇÃO Episcopal em 1988 - Econe 30 de junho. Écône: [s.i.], 1988. (24 min.), son., color. Legendado. Disponível em: $<$ https://www. youtube.com/watch?v=FLyOLq8GDug>. Acesso em: 14 jan. 2020.

SEMINÁRIO DA IMACULADA CONCEIÇÃO. Sobre nós. Disponível em: $<\mathrm{http}$ ://www.seminarioic.org/oseminario/>. Acesso em: 13 set. 2019. UNIÃO SACERDOTAL SÃO JOÃO MARIA VIANNEY. Informe Doutrinário Católicos Apostólicos Romanos: Nossa posição, na atual situação da Igreja. Campos dos Goytacazes: Santuário, 1999. p. 53.

UNIÃO SACERDOTAL SÃO JOÃO MARIA VIANNEY. Missa Nova: Um caso de consciência. Campos dos Goytacazes: Santuário, 2009. p. 2. 